\title{
VIEWPOINT
}

\section{Allocation of Places for Patients to Receive Dialysis in Low and Middle Income Countries: An Ethical Framework for Distributive Justice \\ TS Ferguson}

\begin{abstract}
Access to dialysis and kidney transplantation is limited in low and middle income countries, therefore rationing of dialysis services is usually necessary. Structured rationing systems however are often not in place and even when used may result in ethically irrelevant factors determining who gets dialysis. In this paper 1 propose a dialysis allocation system, based on a modification of the complete lives system, incorporating the following ethical principles: (1) prognosis (saving the most life-years), (2) saving the most lives, (3) age prioritization (for younger patients) and (4) random selection weighted by waiting time. Application of these principles should result in fair and equitable access to dialysis.
\end{abstract}

Keywords: Dialysis, distributive justice, equity, low and middle income countries, public health ethics

From: Caribbean Institute for Health Research, The University of the West Indies, Mona, Kingston Jamaica.

Correspondence: Dr T Ferguson, Caribbean Institute for Health Research, (Epidemiology Research Unit), The University of the West Indies, Kingston 7, Jamaica. Fax: (876) 927 2984, email: trevor.ferguson02@uwimona.edu.jm 


\section{INTRODUCTION}

Access to dialysis and kidney transplantation in low and middle income countries (LMIC) is severely limited due to lack of resources (1-3). In some countries kidney transplantation is not feasible hence dialysis becomes the only option (4-6). While private dialysis services may be an option for some, the majority of patients with end stage kidney disease (ESKD) are unable to afford dialysis and must rely on public dialysis services. Supply of dialysis equipment and trained staff is usually inadequate necessitating some form or rationing $(1,2)$. Structured rationing systems however are often not in place and even when used may result in ethically irrelevant factors determining who gets dialysis. In South Africa, for example, Moosa and Kidd reported that persons most likely to be accepted for dialysis tended to be white, 20-40 years old, employed, non-diabetic and living close to the dialysis centre (1). In this paper I will argue that a modified version of the complete lives system proposed by Persad and colleagues (7) will serve as an ethically permissible and fair dialysis rationing systems for LMIC.

Given that the situation in LMIC is unlikely to improve in the short-term, efforts should be made to develop and implement structured rationing systems. Previously used systems appear to be inadequate and, as seen in South Africa, may result in undesirable outcomes (1). The primary objective of this program is to minimise morbidity and mortality due to ESKD in an ethically permissible and fair way. Questions being considered include: How can we arrive at an ethically permissible and fair allocation system? Can we respect each person's liberty and at the same time produce the maximum benefit to society? 


\section{Recommended allocation system}

Persad and colleagues (7) have recommended the use of a system of allocation for scarce medical interventions called the complete lives system, which uses five individual principles: prioritization of younger patients, prognosis, saving the most lives, lottery and instrumental value of individuals. I propose a modification of this system incorporating the following principles: (1) prognosis (saving the most life-years), (2) saving the most lives, (3) age prioritization (for younger patients) and (4) random selection weighted by waiting time (a variation of the lottery principle). Additionally, I would consider patient autonomy, so that patients could choose whether they want to be considered for dialysis after being fully briefed as to the benefits and risk associated with dialysis.

The allocation system would be administered by an independent committee comprised of physicians, nurses, patients and members of the public. Persons who indicate that they want to be included in the dialysis allocation system would first be assessed by an independent committee who would determine prognosis based on estimated quality adjusted life-years (QALYs). The system would seek to optimize the number of lives saved by adjusting the optimal QALY to give the maximum balance between QALYs gained and the number persons treated. Recognising that younger persons has had the least years lived, the system would be adjusted to favour younger persons, giving priority to persons less than 40 years old.

Priority points would be allocated to each person based on the principles outlined above and summed to give a total priority score. After these conditions has been determined a lottery would be used to randomly select persons for dialysis with the probability of selection weighted by priority score and waiting time. Ideally this would use a computer program to select participants, however in settings where computer programs are not available a manual selection 
could be done with the number of entries determined by priority score and waiting time. This allocation system would be only for stable patients waiting to be placed on long term dialysis. Provisions would also be made for persons to receive emergency dialysis when required.

\section{Ethical justification}

The ethical theories guiding this allocation system is a primarily Rawlsian (egalitarian), but includes utilitarian principles of striving for the maximum benefit to society. Consistent with Rawls Liberty principle, in an egalitarian society all citizens should have equal basic liberties, and that the only inequalities allowed are those that benefit the least advantaged (8). In this system all patients should have equal opportunity to access dialysis, but I would prioritize younger patients due to the disadvantage in years of life lived. The selection of younger patients is based on the fair innings principle (9) where individuals are deemed to be entitled to a 'normal lifespan' of about 70 - 80 years. I have chosen 40 years as the cut-point as this represents about half of the life expectancy in developed countries and is considered by many as the transition from youth to middle age. While some have advocated a lower priority for the very young, e.g. children less than 15 years in the complete lives system (7), I would exclude this criterion in this allocation system, given that the proportion of children under 15 among persons with ESKD is small, and the psychological trauma of denying treatment to children would be difficult to justify to both parents and children. Additionally, these children would be the most disadvantaged from a Rawlsian perspective. The utilitarian view suggest that the morally correct thing to do is that which produces the best state of affairs, or that which maximizes pleasure over pain (10). In this system it is expected that maximum benefit can be obtained by prioritizing persons with the best prognosis, maximizing both the number of QALYs gained and number of lives saved. I have excluded instrumental value in this allocation system because it is not consistent with the equal opportunity 
principle and raises the possibility of ethically irrelevant socio-political considerations. It should be noted that Persad and colleagues suggest that when considering the ethics of rationing, no single principle recognizes all the morally relevant factors, therefore it is necessary to form multiprinciple allocation systems (7). This system would satisfy utilitarian reasoning while at the same time upholding egalitarian principles and the Rawlsian 'difference principle' of prioritization of the worse off. This balancing of equity and utility is generally accepted by the medical community (11).

\section{Counter arguments}

Ethical counter arguments for this system would include that it prioritises young over old and does not include a 'first come first served' and 'sickest first' principles as used in some established allocation systems $(7,11)$. While it may initially seem reasonable to treat people equally regardless of age, this does not take into consideration the fact that the youngest have had the least number of lived years, thus prioritization of the young promotes each persons' right to live through all stages of life and the opportunity for a 'fair innings' of life $(7,9)$. The sickest first principle is counter to the utilitarian view of maximizing utility as the sickest often have the worse prognosis. Additionally, the sickest first policy presumes that scarcity is temporary, which is not the case in LMIC. The first come first served principle while appearing fair initially is subject to manipulation and favours the best-off as persons with higher social standing and those with greater knowledge will get themselves on the list first. As pointed out by Persad and colleagues (7) and Zink and colleagues (11), both these principles are subject to exploitation. Use of a random selection lottery system overcomes the limitations of the first come first served principle, while weighting the probability of selection by waiting time adjust for the lottery's lack of sensitivity to the length of time the patient has been on the list. 
Another potential limitation of this allocation system is that it is fairly cumbersome to administer, requiring computation of prognosis (QALYs) and sophisticated weighting systems to ensure saving the most lives, younger age prioritization and adjustments for waiting time. Additionally, the system would require regular meeting of selection committees with its attendant time burden. In order to be properly run the system would need the development of computerized selection protocols and the services of a statistician. These resources would however be needed mostly in the start-phase and periodic revision phases. In countries where such expertise is not available experts from other countries could be asked to help in the initiation phase. Where computer access is limited prognosis charts could be developed and a manually operated lottery system used. Overall the system should have low risk of being corrupted given its reliance on less subjective allocation procedures.

Potential burdens of this allocation system includes it need for volunteers to administer programme and potential for psychological distress among programme officers. The system will also lead to some anxiety among persons waiting for treatment decisions. These burdens can be minimised by having a revolving system for programme officers, inclusion multiple stakeholders and providing periodic updates for patients on the waiting list. Fair implementation will be ensured by periodic review and report of outcomes from the allocation system. This I believe will lead to an ethically justifiable and fair distribution of dialysis in LMIC. 


\section{EFERENCES}

1. Moosa MR, Kidd M. The dangers of rationing dialysis treatment: the dilemma facing a developing country. Kidney Int 2006; 70:1107-14.

2. White SL, Chadban SJ, Jan S, Chapman JR, Cass A. How can we achieve global equity in provision of renal replacement therapy? Bull World Health Organ 2008; 86: 229-37.

3. Stanifer JW, Muiru A, Jafar TH, Patel UD. Chronic kidney disease in low- and middleincome countries. Nephrol Dial Transplant 2016; 31: 868-74.

4. Exantus J, Desrosiers F, Ternier A, Metayer A, Abel G, Buteau JH. The need for dialysis in Haiti: dream or reality? Blood Purif 2015; 39: 145-50.

5. Soyibo AK, Barton EN. Report from the Caribbean renal registry, 2006. West Indian Med J 2007; 56: 355-63.

6. Soyibo AK, Roberts L, Barton EN. Chronic kidney disease in the Caribbean. West Indian Med J 2011; 60: 464-70.

7. Persad G, Wertheimer A, Emanuel EJ. Principles for allocation of scarce medical interventions. Lancet 2009; 373: 423-31.

8. Sandel MJ. The Case for Equality / John Rawls. In: Justice: What is the right thing to do? Kindle Edition ed: Penguin Books Ltd; 2009: 138-64.

9. Williams A. Inequalities in health and intergenerational equity. Ethical Theory Moral Pract 1999; 2: 47-55.

10. Sandel MJ. The Greatest Happiness Principle / Utilitarianism. In: Justice: What's The Right Thing To Do? Kindle Edition ed: Penguin Books Ltd; 2009: 29-55.

11. Zink S, Wertlieb S, Catalano J, Marwin V. Examining the potential exploitation of UNOS policies. Am J Bioeth 2005; 5: 6-10. 